\title{
Long-term morphological and power spectral studies of VHF amplitude scintillations recorded over Waltair $\left(17.7^{\circ} \mathrm{N}, 83.3^{\circ} \mathrm{E}\right)$, India
}

\author{
Vadlamuri Kanaka Durga Srinivasu ${ }^{1}$, Potula Sree Brahmanandam ${ }^{2, *}$, Gouthu Uma ${ }^{2}$, Dasari Shanmukha \\ Veera Venkata Durga Prasad ${ }^{1}$, Paluri Venkata Satya Rama Rao ${ }^{1, * *}$, and Shyamoli Mukherjee ${ }^{3}$ \\ ${ }^{1}$ Space Physics Labs, Department of Physics, Andhra University, Visakhapatnam, India \\ ${ }^{2}$ Shri Vishnu Engineering College for Women, Vishupur, Bhimavaram, India \\ ${ }^{3}$ Indian Institute of Geomagnetism, Navi Mumbai, India
}

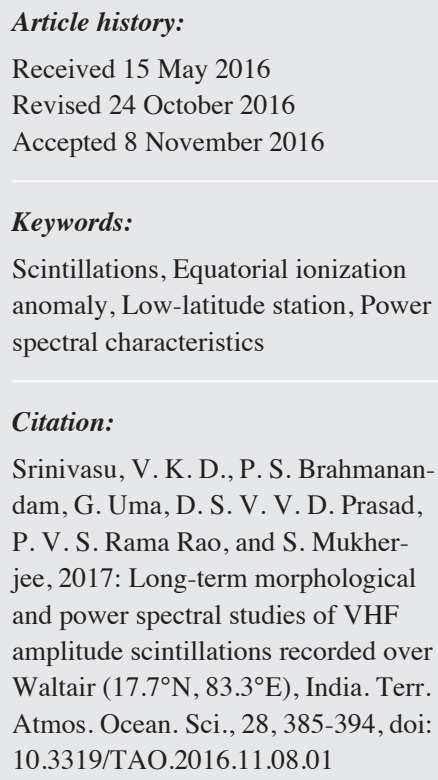

\begin{abstract}
This research reports on recently recorded $250 \mathrm{MHz}$ amplitude scintillations at Waltair $\left(17.7^{\circ} \mathrm{N}, 83.3^{\circ} \mathrm{E}\right)$, a low-latitude station in India, using the signals radiated from a geostationary satellite (FLEETSAT, $73^{\circ} \mathrm{E}$ ) during a six-year period (2008 2013), which covers extremely low and higher solar activity years (2008 and 2013). The morphological features in terms of local time, month, and season during different geophysical conditions are presented. The scintillation patches (segregated based on their occurrence durations) have shown an increasing trend with the increasing sunspot activity. The scintillation patches with 30-min duration show increasing trends with increasing sunspot activity, and their occurrence frequencies also show increasing trends with increasing sunspot activity. The scintillation activity during disturbed epochs (Kp index lies between $3^{+}$and 9 ) is found to be less compared to its quiet day counterparts. The plausible mechanisms for these observational results are discussed. In addition, power spectral characteristics, including Fresnel frequency, upper role of frequency and spectral slope of scintillations are calculated and the salient results are presented.
\end{abstract}

\section{INTRODUCTION}

Small-scale variations in electron density structure in the natural ionosphere can disturb electromagnetic (EM) signals that propagate via ionosphere. These irregularities can cause rapid variation in the amplitude, phase, and other signal properties and such signal variations are usually called scintillations that are usually observed at VHF and UHF bands (Basu et al. 1988). Ionosphere scintillations degrade the performance of satellite-based communications and GPS-based navigation (Groves et al. 1997; Basu et al. 1998, 2002; Doherty et al. 2002). The severe scintillations, for which the scintillation index is usually greater than 0.45 , which is $\approx 10 \mathrm{~dB}$, are able to interrupt the GPS receiver operation by causing in-phase and quadrature signal fading,

\footnotetext{
* Corresponding author

E-mail:dranandpotula@svecw.edu.in

** Deceased
}

which makes the proper phase determination using a tracking loop nearly impossible. Further, it was reported that a typical GPS receiver loses its lock for a short duration from 1 - 4 min during severe scintillation events, thereby affecting even the integrity of satellite based augmentation systems (SBAS) (Rama Rao et al. 2006).

Night time ionospheric density irregularities predominantly develop in the F-layer of the ionosphere, with the primary disturbance region being typically between 250 and $450 \mathrm{~km}$. Many researchers have reported the physical process leading to the formation and evolution of ionospheric irregularities (Woodman 1970; Woodman and La Hoz 1976; Keskinen and Ossakow 1983; Kelley 1989; Fejer 1991; Heelis 2004). Ionospheric irregularities will be generated by various instability processes. A sharp gradient at the bottom side of the F-layer, which is anti-parallel to the gravity acceleration vector (Kelley 1989) and pre-reversal 
enhancement (PRE) in upward $\boldsymbol{E} \times \boldsymbol{B}$ drift and associated uplifting of the F-layer (Rishbeth et al. 1978; Fejer et al. 1999; Whalen 2002) generates density irregularities. A simultaneous decay of the E-region conductivity at both ends of the field line (Tsunoda 1985; Stephan et al. 2002), the trans-equatorial component of thermospheric winds, and associated with symmetry in the Equatorial Ionization Anomaly (EIA) (Maruyama and Matuura 1984; Maruyama 1988; Mendillo et al. 1992,2001) plays an important role to generate ionospheric density irregularities.

The PRE causes rapid uplifting of equatorial F-layer and steepens the bottom side gradient according to the generalized Rayleigh-Taylor instability mechanism, which leads to the generation of ionospheric density irregularities. Primarily large-scale plasma depletions generated in post sunset hours later depleted into smaller scales in the cascade process (Haerendel 1973). These irregularities may have scale sizes from a few centimeters to several hundred kilometers. These irregularities are field aligned, stretched more in the north-south direction up to the anomaly crest than in EastWest direction (Aarons et al. 1980; Das Gupta et al. 1983; Rama Rao et al. 2005). The small-scale irregularities in the 100 - $500 \mathrm{~m}$ size range, which are known to be responsible for producing strong scintillations at L-band frequencies, co-exist with the kilometer scale size irregularities causing intense scintillations with fast fading rates at VHF frequencies. These irregularities can cause strong multiple radio wave scattering. Krishna Moorthy et al. (1979) reported that scintillations with slow fading rates (Class-II) are basically due to irregularities of much larger sizes than scintillations with fast fading rates (Class-I) with smaller scale sizes. The large-scale and relatively weak irregularities are responsible for high fading periods (low fading rates) and low S4-index values in VHF scintillations.

Although it is known to occur in the polar and equatorial regions of the Earth's ionosphere, equatorial scintillation is known to be more severe than polar region scintillation. The equatorial and low latitude ionosphere have two important and distinct features including, the EIA or Appleton (after Edward V. Appleton) ionization anomaly, and an intense form of irregularities in the electron density distribution. At equatorial and low latitude regions, the most significant post-sunset ionospheric electrodynamics plays a great role in irregularities generation and such irregularities show solar activity dependence, seasonal-longitudinal variations, and day-to-day variations (Woodman and La Hoz 1976; Aarons 1977; Yeh and Liu 1982; Maruyama and Matuura 1984; Basu and Basu 1985; Tsunoda 1985). As the seasonal-longitudinal variations are concerned, Maruyama and Matuura (1984) and Tsunoda (1985) proposed excellent theories. Maruyama and Matuura (1984) relied on a transequatorial thermospheric wind, while Tsunoda (1985) used the solar terminator alignment with geomagnetic flux tubes in order to explain the seasonal-longitudinal variations in ionosphere irregularities.

The recording of ionospheric amplitude scintillations has been performed at Waltair $\left(17.7^{\circ} \mathrm{N}, 83.3^{\circ} \mathrm{E}\right)$, India for the last four decades (Rama Rao et al. 1980). We report here on recently recorded amplitude scintillations at $250 \mathrm{MHz}$ during 2008 - 2013 over Waltair, India and present their morphological features and the occurrence characteristics. The power spectral characteristics of scintillations for a few cases during this study period are also presented. Most importantly, one of the years (2008) in the present study belonged to the quietest solar activity occurring during the past 60 years (Singh et al. 2017). Knowing the occurrence of ionosphere irregularities during this unique year over a typical low-latitude station is, surely, an interesting research topic to be understood.

\section{DATA AND METHOD OF ANALYSIS}

The $250 \mathrm{MHz}$ signal amplitude scintillations radiated from a geostationary satellite (FLEETSAT, located at $73^{\circ} \mathrm{E}$ longitude) recorded at Waltair $\left(17.7^{\circ} \mathrm{N}, 83.3^{\circ} \mathrm{E}\right)$, a low latitude Indian station, located within the transition region between the anomaly crest and the magnetic equator (Fig. 1). Figure 1 also shows equatorial and anomaly crest stations in the Indian sector (Trivandrum and Kolkata) along with their geographic and geomagnetic coordinates (see figure for further details). The amplitude scintillation data were recorded continuously at this location over half a solar cycle period (2008 - 2013) and this period belongs to the ascending phase of the $24^{\text {th }}$ solar cycle. The scintillation experimental facility at Waltair consists of a Yagi-Uda antenna, a double super-heterodyne receiver, analog-to-digital converter and associated electronics to convert the received analog signal into digital format. The digital data is stored in a PC for offline processing. The amplitude scintillations were recorded at a sampling rate of $20 \mathrm{~Hz}$.

The percentage occurrence of scintillations during the time period 18:00 - 06:00 LT in each month of the entire period (data available period 1452 days) is presented. S4index and the parameters of power spectral density, such as upper roll of frequency, first Fresnel frequency and spectral slope are calculated. The duration of scintillations patches and the percentage occurrence of scintillations for quiet days $(K p \leq 2)$ and disturbed days $(K p>2)$ in each year are computed. The percentage of occurrence of the S4-index is calculated as the ratio between the total numbers of scintillation observations to the total number of observations during the specific period.

\section{RESULTS AND DISCUSSIONS}

\subsection{Power Spectral Characteristics of Scintillations}

Spectral characteristics of the scintillations are presented in this section as case studies. Power spectral characteristics 
such as upper roll of frequency, first Fresnel frequency, and spectral slopes are calculated and presented as bottom panels in Fig. 2 (28 December 2009), Fig. 3 (13 January 2010), and Fig. 4 (23 March 2013) respectively along with amplitude scintillations and the corresponding scintillation index (S4index) in the top panels. The S4-index is calculated (Briggs and Parkin 1963) with an FFT technique applied to determine the power spectra. Further, a best-fit line of the sloping part of the spectrum is obtained, and noted as the spectral slope $(n)$. The frequencies at which the power begins to decrease are noted as the upper role of frequency $\left(f_{u}\right)$, and this $\mathrm{f}_{\mathrm{u}}$ is related to the Fresnel frequency and the corresponding scale size of the irregularity is the Fresnel scale. In general, the irregularity layer is assumed to be at a typical height of $350 \mathrm{~km}$

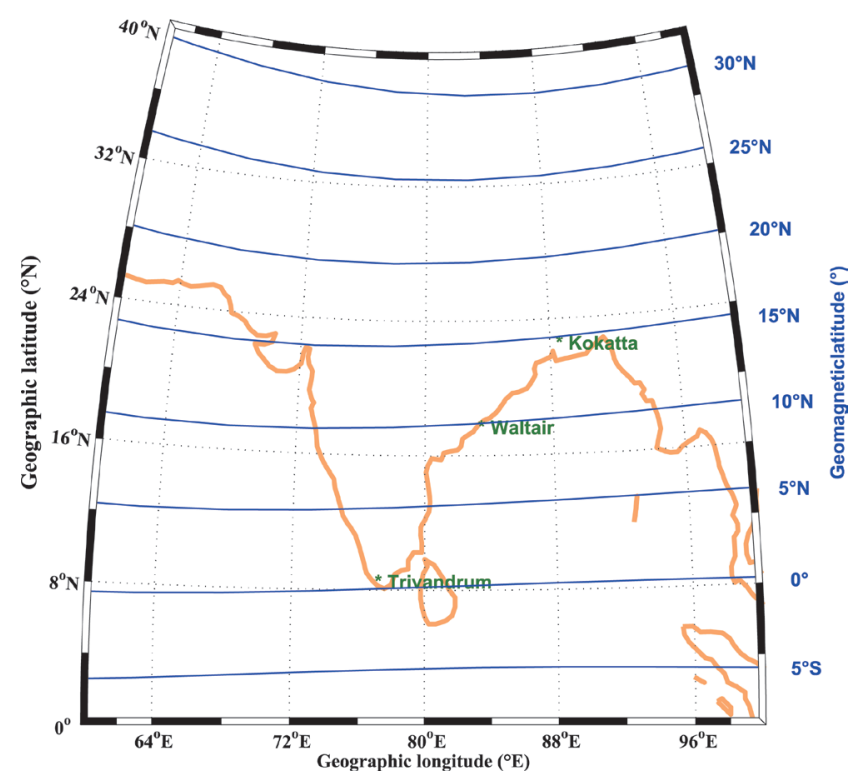

Fig. 1. Geographic and geomagnetic coordinates of a few Indian locations including, Trivandrum (an equatorial station), Waltair (a low-latitude station), and Kolkata (a low-latitude station located at the peak of the Appleton Anomaly region). Geomagnetic coordinates are shown in blue color. (Color online only)
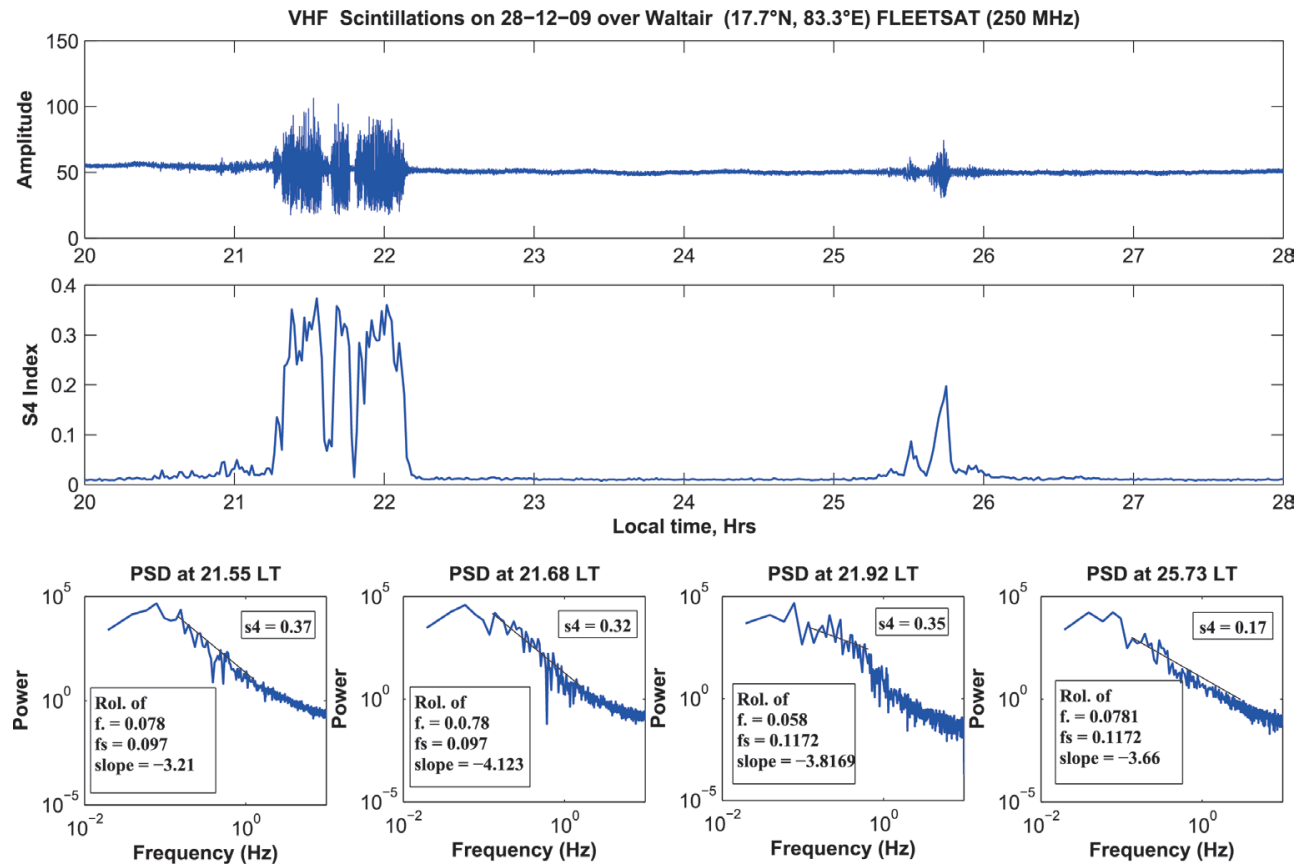

Fig. 2. Amplitude scintillations (top panel) and their scintillation index (S4-index, middle panel) and power spectrums of scintillation patches (bottom panel) recorded at Waltair on 28 December 2009. (Color online only) 

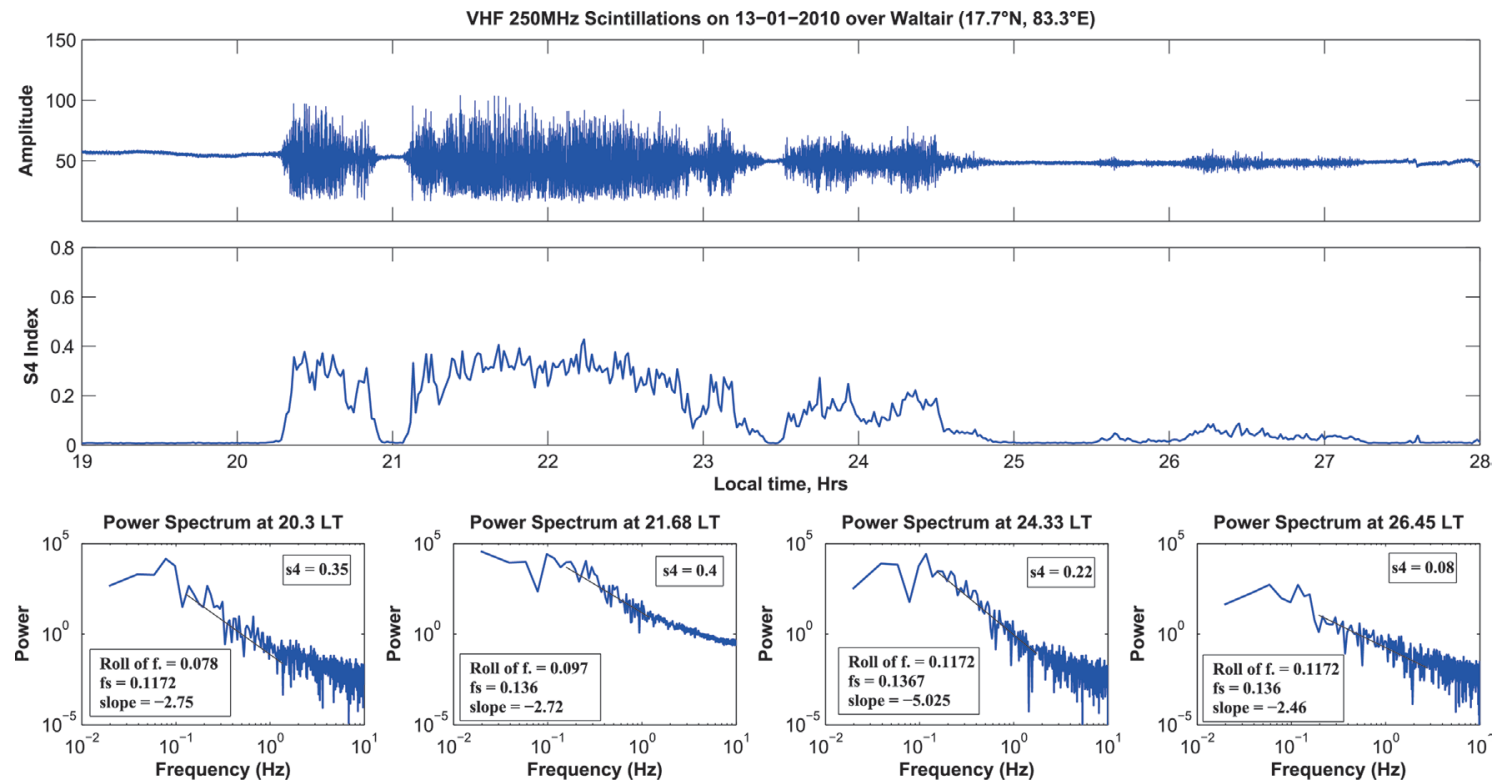

Fig. 3. Amplitude scintillations (top panel) and their scintillation index (S4-index, middle panel)) and power spectrums of scintillation patches (bottom panel) recorded at Waltair on 13 January 2010. (Color online only)
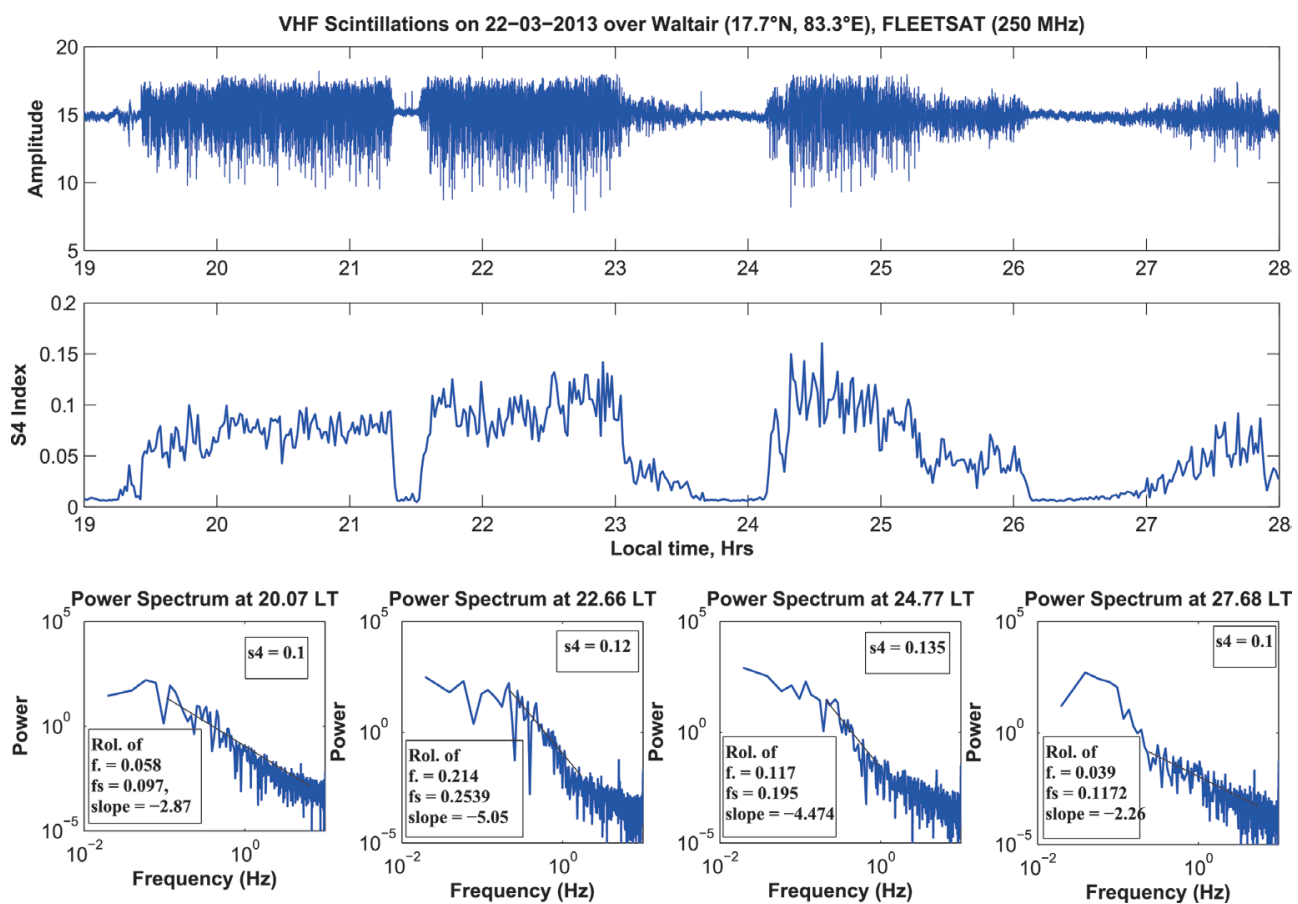

Fig. 4. Amplitude scintillations (top panel) and their scintillation index (S4-index, middle panel) and power spectrums of scintillation patches (bottom panel) recorded at Waltair on 22 March 2013. (Color online only)

and the Fresnel scale $(\sqrt{2 \lambda} z)$ for $250 \mathrm{MHz}(\lambda=1.2 \mathrm{~m})$ is, therefore at $916 \mathrm{~m}$ (Iyer et al. 2006).

Power spectra corresponding to post-sunset scintillations are normally characterized by higher upper roll of frequency followed by steep slopes. The upper roll of frequencies helps us to evaluate the scale sizes of the irregularities through $(\sqrt{2 \lambda} z)$. The upper roll of frequencies of the spectrum corresponding to post sun-set hours ranged from $0.058-0.214 \mathrm{~Hz}$. The lower Fresnel Break frequency values $\left(f_{B}\right)$ during the post-midnight hours indicated that there is a reduction in the forward scatter power, and, as a result, only large scale irregularities were contributed to initiate the VHF scintillations (Basu et al. 1980) observed in the present research. Power spectra with steep high frequency roll off 
mainly indicate scattering from multiple structures of different scale sizes (Franke and Liu 1983).

The spectral slopes of the power spectrum in the present study are observed in the range between 2.26 and 5.05. Steep spectral slope as high as 6 for early evening scintillations at $257 \mathrm{MHz}$ near the solar maximum period equatorial regions were reported by Basu and Coppi (1983). Iyer et al. (2006) reported scintillations in the range between 2.5 and 5.6 from the equatorial anomaly region. The scintillation power spectra, under the thin screen assumption, indicate the scale size distribution. Higher (lower) spectral slopes indicate the quick (gradual) decrease of small scale irregularities. From the temporal spectra of several scintillation patches, it was found that plasma bubbles induced VHF scintillations exhibiting a flat, low-frequency region, and steep roll off (with slopes in between 3 and 5) in the high frequency region. The first Fresnel minimum $f_{1}=V_{0} / \sqrt{\lambda_{z}}$ has been shown (Rufenach 1972; Yeh and Liu 1982), where $z$ is the slant range of the observer to irregular layer, $V_{0}$ is the irregularity velocity normal to propagation path. The first three Fresnel minima are observed at $f_{1}, \sqrt{2 f_{1}}, \sqrt{3 f_{1}}$. The presence of Fresnel oscillations in the power spectrum may be an indicative of a thin layer $<100 \mathrm{~km}$ (Rama Rao et al. 2005). The top panels in Figs. 2, 3, and 4 present the amplitude scintillations and the corresponding scintillation index (S4-index) variation in local time. The bottom four panels in each figure represent the power spectrum of 2 min data segment of each scintillation patch during 28 December 2009, 13 January 2010, and 23 March 2013.

From the top panel of Fig. 2 only one scintillation patch with short-duration $(<1 \mathrm{~h})$ is observed between 2120 and 2210 hrs LT on 28 December 2009, while both long and short duration patches are seen on 13 January 2010 (less than 30 minutes and two hours) and 22 March 2013 (more than half an hour to two hours). Figures 2 and 3 show that the scintillations are moderate (S4-index lies between 0.3 and 0.5), while the scintillations on 22 March 2013 (Fig. 1) are low (S4-index lies between 0.05 and 0.15). Amplitude scintillations recorded on 28 December 2009 (Fig. 2) show fast fading rates varying between $\sim 18$ and $\sim 32$ fad $\min ^{-1}$ $\left(\sim 0.30\right.$ and 0.53 cycles $\left.\mathrm{s}^{-1}\right)$, while the scintillations recorded on 13 January 2010 (Fig. 3) are showing moderate fade rates that vary between $\sim 7$ and $\sim 23 \mathrm{fad} \mathrm{min}^{-1}(\sim 0.11$ and 0.38 cycles s$\left.^{-1}\right)$, and the fading rates of scintillations recorded on 22 March 2013 (Fig. 4) are low, with values varying

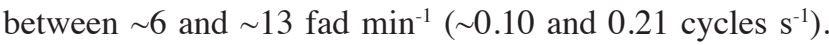
The spectral characteristics along with fade rates on 28 December 2009, 13 January 2010, and 23 March 2013 are presented in Table 1.

As the moderate intensity and relatively fast fading rates of VHF scintillations are due to multiple scattered radio waves with a wide range of irregularities embedded in plasma bubbles, which are moving across the FLEETSAT satellite propagation path, the observed scintillations in the present study would have originated from a wide range of irregularities that were initiated initially over the equatorial station (Iyer et al. 2006; Rama Rao et al. 2006; Basu et al. 2009; Prasad et al. 2012).

\subsection{Monthly Occurrence of Scintillations over Waltair during 2008 - 2013}

The percentage occurrence of scintillations over Waltair over half a solar cycle period (2008 - 2013) from 18:00 to 06:00 LT is presented in Fig. 5. It is observed from these figures that the month to month variation in scintillation shows a maximum in the equinox, moderate occurrence during winter and minimum in the summer months. It is interesting to note that during the vernal equinox months (March and September) of the year 2008, the scintillation activity is less, while the autumn equinox months show a reasonably good percentage occurrence $(\sim 30 \%)$. There are many reports on the morphology of ionospheric irregularities in the Indian sector, which include the diurnal, solar cycle, season and geomagnetic activity related variations. Most importantly, an inimitable feature of the incidence of ionospheric irregularities in the Indian sector is the solar activity dependent seasonal behavior (Subbarao and Murthy 1994; Sreeja et al. 2009; Prasad et al. 2012). In an elaborate sense, the occurrence of ionospheric irregularities maximizes in the post-sunset periods and is more probable during the equinox season of higher solar activity epochs, while during the summer solstice of low solar activity periods, the peak occurrence in the incidence of irregularities during the postmidnight period is a general observational finding. Though extreme low solar activity occurred during 2008, (the average F10.7 index value during 2008 was mere 66 only) could be the one of the plausible reasons for the very low percentage occurrence of scintillations. The exact physics behind this feature cannot be understood from this research and must be verified from other databases, including the COSMIC radio occultation technique (Liu et al. 2008; Potula et al. 2011; Brahmanandam et al. 2012) as a future study.

Further, the scintillation activity is higher $(62 \%)$ in October 2012 (the average F10.7 index during October 2012 was 113), which is the highest among all months of the entire period of observation. Another important observation is that with the increase in solar activity, scintillation activity also enhances, which corroborates with earlier research studies (Subbarao and Murthy 1994; Sreeja et al. 2009; Prasad et al. 2012). In addition, there is an appreciable change in onset timings between low (2008 and 2009) and high (2012 and 2013) solar activity years. For instance, the ionospheric scintillations appeared at 1900 LT or beyond during low sunspot years (including 2008, 2009, 2010), while these were started around 1800 LT during moderately high sunspot years $(2011,2012,2013)$. This can be understood as follows: The irregularity amplitude $\Delta N / N$ (where $\Delta N$ is 
Table 1. Various spectral parameters of the observed scintillations.

\begin{tabular}{|c|c|c|c|c|c|c|c|c|c|}
\hline $\begin{array}{l}\text { S. } \\
\text { No. }\end{array}$ & Date & $\begin{array}{c}\text { Time of PSD } \\
\text { (Hrs.LT) }\end{array}$ & S4-index & $\begin{array}{l}\text { Upper Roll of } \\
\text { frequency }(\mathrm{Hz})\end{array}$ & $\begin{array}{c}\text { Fresnel frequency } \\
(\mathrm{Hz})\end{array}$ & $\begin{array}{c}\text { Spectral } \\
\text { slope }\end{array}$ & $\begin{array}{c}\text { Patch Duration } \\
\text { (min) }\end{array}$ & $\begin{array}{l}\text { Fade rate of sig- } \\
\text { nal (fade/min) }\end{array}$ & $\begin{array}{r}\text { Peak-to-peak } \\
\text { amplitude (dB) }\end{array}$ \\
\hline \multirow{4}{*}{1} & \multirow{4}{*}{$22-03-2013$} & 20.07 & 0.10 & 0.058 & 0.197 & -2.87 & 98 & 13 & 1.76 \\
\hline & & 22.66 & 0.12 & 0.214 & 0.253 & -5.05 & 87 & 12 & 2.1 \\
\hline & & 24.77 & 0.13 & 0.117 & 0.195 & -4.47 & 118 & 9 & 2.29 \\
\hline & & 27.68 & 0.10 & 0.039 & 0.117 & -2.26 & 53 & 6 & 1.76 \\
\hline \multirow{4}{*}{2} & \multirow{4}{*}{$13-01-2010$} & 20.3 & 0.35 & 0.078 & 0.117 & -2.75 & 37 & 18 & 6.17 \\
\hline & & 21.68 & 0.40 & 0.097 & 0.136 & -2.72 & 136 & 23 & 7.05 \\
\hline & & 24.33 & 0.22 & 0.117 & 0.136 & -5.03 & 58 & 15 & 3.88 \\
\hline & & 26.55 & 0.08 & 0.117 & 0.136 & -2.46 & 38 & 7 & 1.41 \\
\hline \multirow{4}{*}{3} & \multirow{4}{*}{$28-12-2009$} & 21.55 & 0.37 & 0.078 & 0.097 & -3.12 & 20 & 22 & 6.52 \\
\hline & & 21.68 & 0.32 & 0.078 & 0.097 & -4.12 & 14 & 26 & 5.64 \\
\hline & & 21.92 & 0.35 & 0.058 & 0.1172 & -3.82 & 26 & 32 & 6.17 \\
\hline & & 25.72 & 0.17 & 0.078 & 0.1172 & -3.66 & 19 & 18 & 3 \\
\hline
\end{tabular}
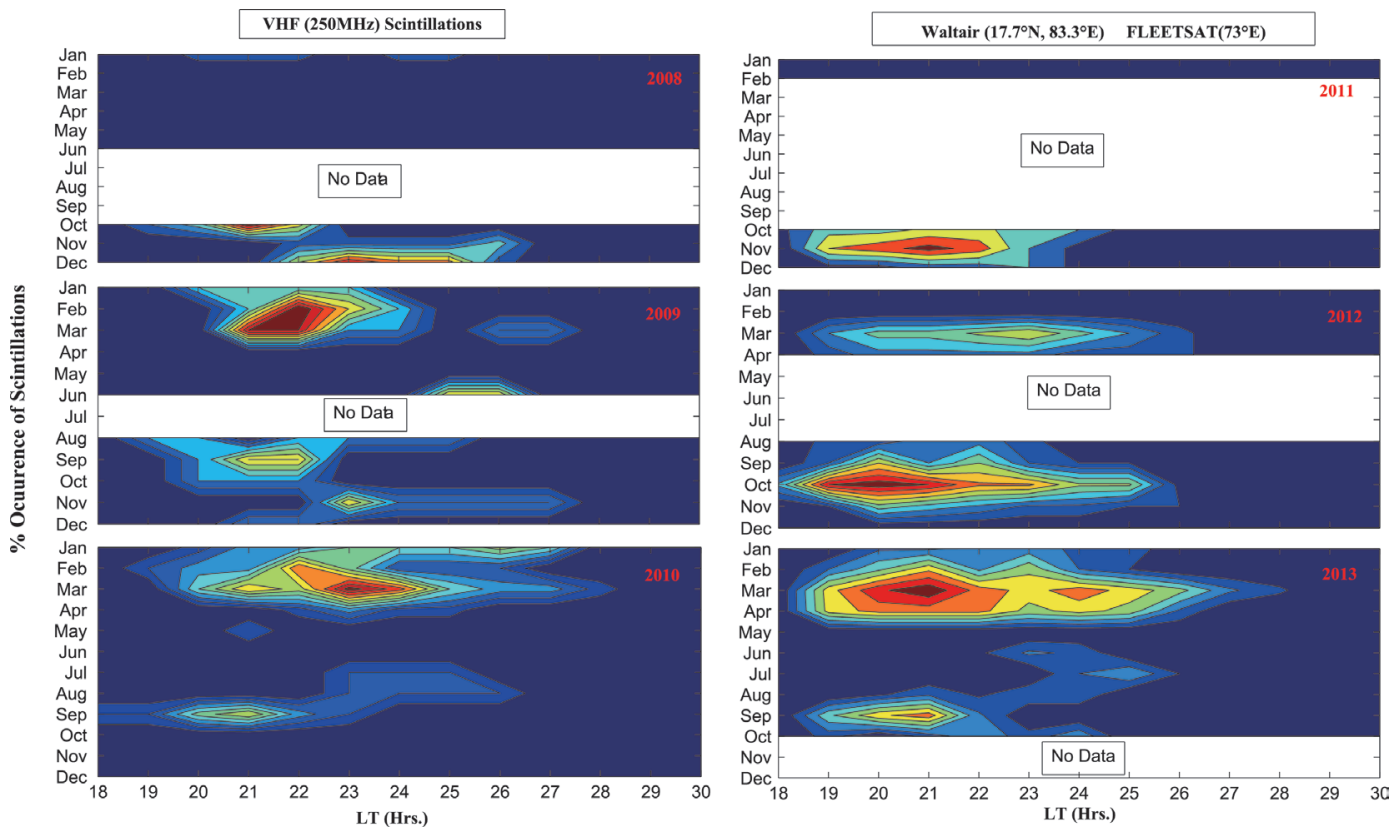

Fig. 5. Contour diagrams showing monthly percentage occurrence of VHF Scintillations during 2008 - 2013. (Color online only)

the irregularity strength and $N$ is the background density) did not vary much with solar activity, but the background density $(N)$ in the solar maximum period increased at least 10 fold. Therefore, the scintillation activity was enhanced due to the increase in background density during the higher solar activity period, and the onset timing could have also appeared earlier (Basu and Basu 1985; Iyer et al. 2006).

\subsection{Distribution of Scintillation Patch Durations}

The zonal (east-west) drift velocities combined with the scintillation patch duration in the east-west irregularities size intent can be computed using the following simple relation: $\mathrm{E}-\mathrm{W}$ extent $=$ zonal drift velocity $\mathrm{x}$ patch duration [assuming that the irregularity structure will not change much within such short duration of 5-8 min (Rama Rao et al.
2000)]. By realizing the importance of the scintillation patch duration, we have segregated the scintillation patches belonging to different local times and patch duration distribution in Fig. 6. Each panel in Fig. 6 shows the patch duration statistics observed in a specific year, with the yearly mean sunspot number (YMSN) and the total number of patches observed. A total of 473 scintillation patches were observed with patch duration ranging from $5-210 \mathrm{~min}$ (three and half hours) during the present period (2008 - 2013). The important observation is that the number of patches is increasing with increasing sunspot activity. A total of about 20 scintillation patches have been observed during a low sunspot year (2008) while more than 155 scintillation patches were noted during a high sunspot year (2013). The most probable scintillation patch duration with less than $30 \mathrm{~min}$ is about $44 \%$, while only $1 \%$ in the case of scintillation patches with 
durations greater than $181-210 \mathrm{~min}$.

The short duration patches were associated with spread-F range type on ionograms (Yeh et al. 1979; Basu et al. 1986). The maximum plasma bubble induced (PBI) scintillations occur during the post sunset hours of equinoctial months and appear mostly as several short duration patches of 5 - 30 min in duration. The bottom side sinusoidal (BSS) irregularity type maximize around the post sunset hours of summer solstice months (May, June, July, and August) and is generally characterized by long duration patches of 3 hours or more (Das Gupta et al. 1983). The longer patch durations suggest that the BSS irregularities extend to a few thousand kilometers in the east-west direction (Valladares et al. 1983) and the PBI type irregularities have east-west dimensions ranging from $100-500 \mathrm{~km}$ in most cases.

\subsection{Effect of Magnetic Activity on Scintillation Occurrence}

With a view to studying the magnetic activity effect on the scintillation percentage occurrence for quiet days $(\mathrm{Kp}=0-3)$ and magnetically disturbed days $\left(\mathrm{Kp}=3^{+}-9\right)$ in each year was computed and presented as histograms in Fig. 7. Out of 1452 days of observations, 296 days were
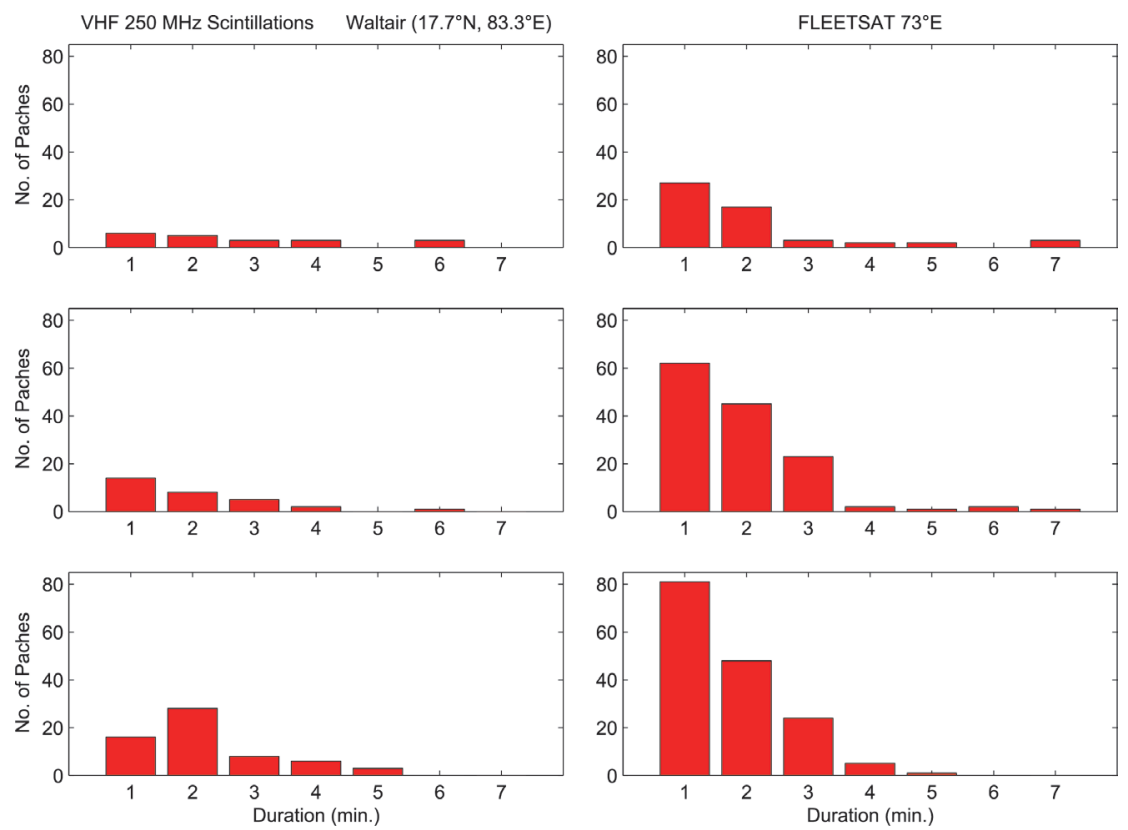

Fig. 6. Distribution of scintillation patch durations observed at Waltair during 2008 - 2013. (Color online only)
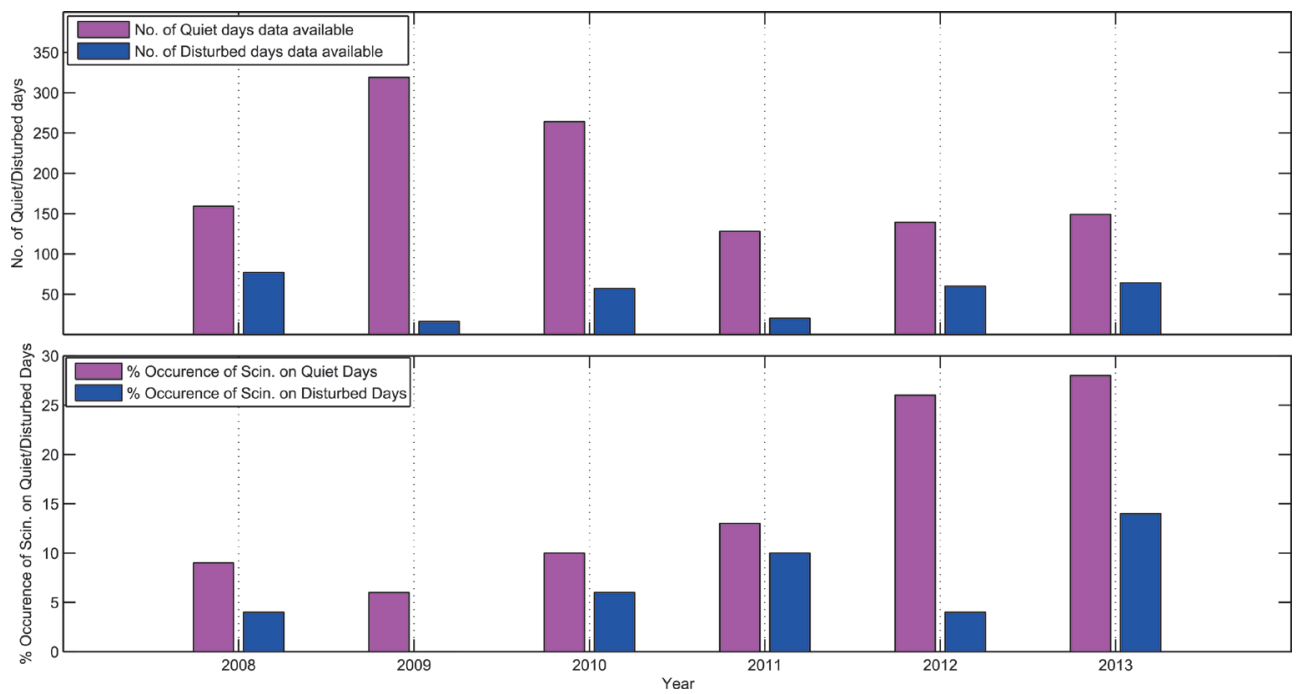

Fig. 7. Occurrence of scintillations during quiet and disturbed days at Waltair during 2008 - 2013. (Color online only) 
magnetically disturbed days. The percentage of scintillation occurrence during quiet days is about $13 \%$, while during magnetically disturbed days it is $7 \%$. The scintillation activity in general during quiet days increases with an increase in solar activity during the present observation period. It is observed that the scintillation percentage occurrence during quiet days is minimized (6\%) in 2009 and maximized (28\%) in 2013. It is important to note that there were no scintillation activity during magnetically disturbed days in the year $2009($ YMSN = 3. 1). The scintillation activity during disturbed days was maximum (14\%) in 2013. The low scintillation occurrence percentage during disturbed periods compared to quiet days is corroborated with earlier results reported from this station (Prasad et al. 2004) and from other low (Bhopal) and moderately mid-latitude stations in India, which include, Varanasi and Agra (Kumar et al. 1993; Kumar and Gwal 2000).

\section{SUMMARY}

We presented recently recorded amplitude scintillations at VHF band $(250 \mathrm{MHz})$ using signals radiated from a geostationary satellite, FLEETSAT $\left(73^{\circ} \mathrm{E}\right)$, in this study for more than six continuous years $(2008$ - 2013) over Waltair $\left(17.7^{\circ} \mathrm{N}, 83.3^{\circ} \mathrm{E}\right)$, a low-latitude station in India. The observational results of this study are summarized as follows:

(1) The morphological features in terms of local time, month, season, and during different geophysical conditions are presented, which obey the earlier studies reported from this station as well as from other Indian stations

(2) The amplitude scintillation index in terms of S4-index and the parameters of power spectral density, such as upper roll of frequency, first Fresnel frequency and spectral slope are calculated and the observational results are presented

(3) Although the scintillation patches are distributed in the $30-210$ min duration range, the 30 min scintillation patches show higher occurrences

(4) Further, the 30-min duration scintillation patches show increasing tendencies with the increase in solar activity.

(5) It is found that the percentage occurrence of scintillations during quiet days is more when compared to magnetically disturbed days.

(6) The power spectral characteristics of amplitude scintillations are presented and some of their important observational results are discussed in light of the available literature.

Acknowledgements One of the authors (VKDS) wishes to express his sincere thanks to UGC for providing him with a UGC-BSR Junior Research Fellowship. Further, Dr. G. Uma is very grateful to the Department of Science \& Technology (DST), Government of India for providing a Women Scientist Scheme-A (File no: SR/WOS-A/EA-1015/2015) project.

\section{REFERENCES}

Aarons, J., 1977: Equatorial scintillations: A review. IEEE Trans. Antennas Propag., 25, 729-736, doi: 10.1109/ TAP.1977.1141649. [Link]

Aarons, J., J. P. Mullen, and H. E. Whitney, 1980: The dynamics of equatorial irregularity patch formation, motion, and decay. J. Geophys. Res., 85, 139-149, doi: 10.1029/JA085iA01p00139. [Link]

Basu, B. and B. Coppi, 1983: Localized plasma depletion in the ionosphere and the equatorial spread F. Geophys. Res. Lett., 10, 900-903, doi: 10.1029/ GL010i009p00900. [Link]

Basu, S. and S. Basu, 1985: Equatorial scintillations: Advances since ISEA-6. J. Atmos. Terr. Phys., 47, 753768, doi: 10.1016/0021-9169(85)90052-2. [Link]

Basu, S., J. P. McClure, S. Basu, W. B. Hanson, and J. Aarons, 1980: Coordinated study of equatorial scintillation and in situ and radar observations of nighttime $F$ region irregularities. J. Geophys. Res., 85, 5119-5130, doi: 10.1029/JA085iA10p05119. [Link]

Basu, S., Su. Basu, and C. E. Valladares, 1986: Scintillations associated with bottomside sinusoidal irregularities in the equatorial $F$ region. J. Geophys. Res., 91, 270-276, doi: 10.1029/JA091iA01p00270. [Link]

Basu, S., E. MacKenzie, and S. Basu, 1988: Ionospheric constraints on VHF/UHF communications links during solar maximum and minimum periods. Radio Sci., 23, 363-378, doi: 10.1029/RS023i003p00363. [Link]

Basu, S., E. J. Weber, T. W. Bullett, M. J. Keskinen, E. MacKenzie, P. Doherty, R. Sheehan, H. Kuenzler, P. Ning, and J. Bongiolatti, 1998: Characteristics of plasma structuring in the cusp/cleft region at Svalbard. Radio Sci., 33, 1885-1899, doi: 10.1029/98RS01597. [Link]

Basu, S., K. M. Groves, Su. Basu, and P. J. Sultan, 2002: Specification and forecasting of scintillations in communication/navigation links: Current status and future plans. J. Atmos. Sol.-Terr. Phys., 64, 1745-1754, doi: 10.1016/S1364-6826(02)00124-4. [Link]

Basu, S., S. Basu, J. Huba, J. Krall, S. E. McDonald, J. J. Makela, E. S. Miller, S. Ray, and K. Groves, 2009: Dayto-day variability of the equatorial ionization anomaly and scintillations at dusk observed by GUVI and modeling by SAMI3. J. Geophys. Res., 114, A04302, doi: 10.1029/2008JA013899. [Link]

Brahmanandam, P. S., G. Uma, J. Y. Liu, Y. H. Chu, N. S. M. P. Latha Devi, and Y. Kakinami, 2012: Global S4 index variations observed using FORMOSAT-3/COSMIC GPS RO technique during a solar minimum year. J. Geophys. Res., 117, A09322, doi: 10.1029/2012JA017966. [Link]

Briggs, B. H. and I. A. Parkin, 1963: On the variation of radio star and satellite scintillations with zenith angle. 
J. Atmos. Terr. Phys., 25, 339-366, doi: 10.1016/00219169(63)90150-8. [Link]

Das Gupta, A., S. Basu, J. Aarons, J. A. Klobuchar, S. Basu, and A. Bushby, 1983: VHF amplitude scintillations and associated electron content depletions as observed at Arequipa, Peru. J. Atmos. Terr. Phys., 45, 15-26, doi: 10.1016/S0021-9169(83)80003-8. [Link]

Doherty, P. H., T. Dehel, J. A. Klobuchar, S. H. Delay, S. Datta-Barua, E. R. de Paula, and F. S. Rodrigues, 2002: Ionospheric effects on low-latitude space-based augmentation systems. Proceedings of the 15th International Technical Meeting of the Satellite Division of The Institute of Navigation (ION GPS 2002), Portland, OR, 1321-1329.

Fejer, B. G., 1991: Low latitude electrodynamic plasma drifts: A review. J. Atmos. Terr. Phys., 53, 677-693, doi: 10.1016/0021-9169(91)90121-M. [Link]

Fejer, B. G., L. Scherliess, and E. R. de Paula, 1999: Effects of the vertical plasma drift velocity on the generation and evolution of equatorial Spread F. J. Geophys. Res., 104, 19859-19869, doi: 10.1029/1999JA900271. [Link]

Franke, S. J. and C. H. Liu, 1983: Observations and modeling of multi-frequency VHF and GHZ scintillations in the equatorial region. J. Geophys. Res., 88, 7075-7085, doi: 10.1029/JA088iA09p07075. [Link]

Groves, K. M., S. Basu, E. J. Weber, M. Smitham, H. Kuenzler, C. E. Valladares, R. Sheehan, E. Mackenzie, J. A. Secan, P. Ning, W. J. McNeill, D. W. Moonan, and M. J. Kendra, 1997: Equatorial scintillation and systems support. Radio Sci., 32, 2047-2064, doi: 10.1029/97RS00836. [Link]

Haerendel, G., 1973: Theory of equatorial spread F, Report. Max-Planck Inst. für Phys. Astrophys., Federal Republic of Germany.

Heelis, R. A., 2004: Electrodynamics in the low and middle latitude ionosphere: A tutorial. J. Atmos. Sol.-Terr. Phys., 66, 825-838, doi: 10.1016/j.jastp.2004.01.034. [Link]

Iyer, K. N., M. N. Jivani, M. A. Abdu, H. P. Joshi, and M. Aggarwal, 2006: Power spectral studies of VHF ionospheric scintillations near the crest of the equatorial anomaly in India. Indian J. Rad. Space Phys., 35, 234-241.

Kelley, M. C., 1989: The Earth's Ionosphere: Plasma Physics and Electrodynamics, Academic Press, San Diego, $500 \mathrm{pp}$.

Keskinen, M. J. and S. L. Ossakow, 1983: Theories of highlatitude ionospheric irregularities: A review. Radio Sci., 18, 1077-1091, doi: 10.1029/RS018i006p01077. [Link]

Krishna Moorthy, K., C. R. Reddi, and B. V. Krishna Murthy, 1979: Night-time ionospheric scintillations at the magnetic equator. J. Atmos. Terr. Phys., 41, 123-134, doi: 10.1016/0021-9169(79)90004-7. [Link]

Kumar, S. and A. K. Gwal, 2000: VHF ionospheric scintillations near the equatorial anomaly crest: Solar and magnetic activity effects. J. Atmos. Sol.-Terr. Phys., 62, 157-167, doi: 10.1016/S1364-6826(99)00090-5. [Link]

Kumar, S., A. K. Singh, P. Chauhan, A. K. Gwal, B. Singh, and R. P. Singh, 1993: Multistation analysis of VHF radio wave scintillations at low latitudes. Indian $J$. Rad. Space Phys., 22, 267-267.

Liu, L., M. He, W. Wan, and M. L. Zhang, 2008: Topside ionospheric scale heights retrieved from Constellation Observing System for Meteorology, Ionosphere, and Climate radio occultation measurements. J. Geophys. Res., 113, A10304, doi: 10.1029/2008JA013490. [Link]

Maruyama, T., 1988: A diagnostic model for equatorial spread $F$. 1. Model description and application to electric field and neutral wind effects. J. Geophys. Res., 93, 14611-14622, doi: 10.1029/JA093iA12p14611. [Link]

Maruyama, T. and N. Matuura, 1984: Longitudinal variability of annual changes in activity of equatorial spread $F$ and plasma bubbles. J. Geophys. Res., 89, 1090310912, doi: 10.1029/JA089iA12p10903. [Link]

Mendillo, M., J. Baumgardner, X. Pi, P. J. Sultan, and R. Tsunoda, 1992: Onset conditions for equatorial Spread F. J. Geophys. Res., 97, 13865-13876, doi: 10.1029/92JA00647. [Link]

Mendillo, M., J. Meriwether, and M. Biondi, 2001: Testing the thermospheric neutral wind suppression mechanism for day-to-day variability of equatorial Spread F. J. Geophys. Res., 106, 3655-3663, doi: 10.1029/2000JA000148. [Link]

Potula, B. S., Y. H. Chu, G. Uma, H. P. Hsia, and K. H. $\mathrm{Wu}, 2011:$ A global comparative study on the ionospheric measurements between COSMIC radio occultation technique and IRI model. J. Geophys. Res., 116, A02310, doi: 10.1029/2010JA015814. [Link]

Prasad, D. S. V. V. D., P. S. Brahmanandam, K. Venkateswarlu, K. Niranjan, and P. V. S. Rama Rao, 2004: Characteristics of VHF scintillations in the Indian equatorial and low latitude stations. Indian J. Rad. Space Phys., 33, 158-169.

Prasad, S. N. V. S., P. V. S. Rama Rao, D. S. V. V. D. Prasad, K. Venkatesh, and K. Niranjan, 2012: Morphological studies on ionospheric VHF scintillations over an Indian low latitude station during a solar cycle period (2001-2010). Adv. Space Res., 50, 56-69, doi: 10.1016/j.asr.2012.03.020. [Link]

Rama Rao, P. V. S., B. V. S. P. Rao, A. Maitra, and D. Gupta, 1980: Simultaneous observations on VHF scintillations from Waltair and Calcutta. Indian J. Rad. Space Phys., 9, 63-64.

Rama Rao, P. V. S., B. V. Ramana Rao, and D. S. V. V. 
D. Prasad, 2000: A study on the zonal movements of ionospheric irregularities using two simultaneous geostationary satellite signals. Indian J.Rad. Space Phys., 29, 66-70.

Rama Rao, P. V. S., S. Tulasi Ram, K. Niranjan, D. S. V. V. D. Prasad, S. Gopi Krishna, and N. K. M. Lakshmi, 2005: VHF and L-band scintillation characteristics over an Indian low latitude station, Waltair $\left(17.7^{\circ} \mathrm{N}\right.$, 83.3ㄹ). Ann. Geophys., 23, 2457-2464, doi: 10.5194/ angeo-23-2457-2005. [Link]

Rama Rao, P. V. S., S. Tulasi Ram, S. Gopi Krishna, K. Niranjan, and D. S. V. V. D. Prasad, 2006: Morphological and Spectral Characteristics of L-band and VHF scintillations and their impact on trans-ionospheric communications. Earth Planets Space, 58, 895-904, doi: 10.1186/BF03351994. [Link]

Rishbeth, H., S. Ganguly, and J. C. G. Walker, 1978: Fieldaligned and field-perpendicular velocities in the ionospheric F2-layer. J. Atmos. Terr. Phys., 40, 767-784, doi: 10.1016/0021-9169(78)90028-4. [Link]

Rufenach, C. L., 1972: Power-law wavenumber spectrum deduced from ionospheric scintillation observations. J. Geophys. Res., 77, 4761-4772, doi: 10.1029/ JA077i025p04761. [Link]

Singh, S. B., V. S. Rathore, A. K. Singh, and A. K. Singh, 2017: Ionospheric irregularities at low latitude using VHF scintillations during extreme low solar activity period (2008-2010). Acta Geodaetica et Geophysica, 52, 35-51, doi: 10.1007/s40328-016-0168-2. [Link]

Sreeja, V., C. V. Devasia, S. Ravindran, T. K. Pant, and R. Sridharan, 2009: Response of the equatorial and lowlatitude ionosphere in the Indian sector to the geomagnetic storms of January 2005. J. Geophys. Res., 114, A06314, doi: 10.1029/2009JA014179. [Link]
Stephan, A. W., M. Colerico, M. Mendillo, B. W. Reinisch, and D. Anderson, 2002: Suppression of equatorial spread $F$ by sporadic $E$. J. Geophys. Res., 107, doi: 10.1029/2001JA000162. [Link]

Subbarao, K. S. V. and B. V. K. Murthy, 1994: Seasonal Variations of Equatorial spread-F. Ann. Geophys., 12, 33-39, doi: 10.1007/s00585-994-0033-4. [Link]

Tsunoda, R. T., 1985: Control of the seasonal and longitudinal occurrence of equatorial scintillations by the longitudinal gradient in integrated $E$ region Pedersen conductivity. J. Geophys. Res., 90, 447-456, doi: 10.1029/ JA090iA01p00447. [Link]

Valladares, C. E., W. B. Hanson, J. P. McClure, and B. L. Cragin, 1983: Bottomside sinusoidal irregularities in the equatorial F region. J. Geophys. Res., 88, 80258042, doi: 10.1029/JA088iA10p08025. [Link]

Whalen, J. A., 2002: Dependence of equatorial bubbles and bottomside Spread F on season, magnetic activity, and $\mathrm{E} \times \mathrm{B}$ drift velocity during solar maximum. J. Geophys. Res., 107, doi: 10.1029/2001JA000039. [Link]

Woodman, R. F., 1970: Vertical drift velocities and eastwest electric fields at the magnetic equator.J. Geophys. Res., 75, 6249-6259, doi: 10.1029/JA075i031p06249. [Link]

Woodman, R. F. and C. La Hoz, 1976: Radar observations of $F$ region equatorial irregularities. J. Geophys. Res., 81, 5447-5466, doi: 10.1029/JA081i031p05447. [Link]

Yeh, K. C. and C. H. Liu, 1982: Radio wave scintillations in the ionosphere. Proc. IEEE, 70, 324-360, doi: 10.1109/ PROC.1982.12313. [Link]

Yeh, K. C., H. Soicher, C. H. Liu, and E. Bonelli, 1979: Ionospheric bubbles observed by the Faraday rotation method at Natal, Brazil. Geophys. Res. Lett., 6, 473475, doi: 10.1029/GL006i006p00473. [Link] 